\title{
Characterisation of Bay of Bengal Cyclones Using IBTrACS Data
}

\author{
Mohammedali Nellayaputhenpeedika ${ }^{1}$, V. Radhakrishnan ${ }^{2}$ \\ Department of Marine Science, Bharathidasan University, Tiruchirappalli-620024 INDIA ${ }^{1,2}$ \\ Email:vrkgeologist@gmail.com ${ }^{2}$
}

\begin{abstract}
Bay of Bengal (BoB) cyclone tracking from a 30-year (1986 to 2016) data, including culling out of data on variables like wind speed, pressure and time stamp from International Best Track Archive for Climate Stewardship (IBTrACS) and processing the same for the production of graphs, charts and maps on a chosen resolution are challenging. MATLAB code minimized strain and diligence in deciphering spatial correlation and variability of BoB cyclones. High wind speed and low-pressure regimes in northeastern BoB caused cyclones in large numbers during October and November. February recorded a few cyclones. Data analyses revealed a decreasing trend of cyclones over Bay of Bengal.
\end{abstract}

Keywords- Bay of Bengal, Low-pressure systems, Cyclone tracking, Tropical Cyclone, Cyclone trend, Cyclone climatology, Cyclone landfall.

\section{INTRODUCTION}

One of the natural hazards, the cyclones - variously called at different geographic regions as typhoons, storms, and hurricanes - are transitory wind structures with enormous power of destruction to cause loss of life and property. As cyclones follow tropical climate zone matching equatorial swath of the earth, they are also called tropical cyclones (TC). Cyclones are spiralling air-masses with high wind speed. Bay of Bengal occupies centre stage for its numerous seasonal and off-seasonal cyclones that are promoted by vagaries in temperature regimes over it. Across $\mathrm{BoB}$, cyclones originate, intensify, migrate, landfall and dissipate. Their traverse is generally from east to west.

World countries name cyclones for easy reference. In this research work, cyclones Vardha, Nargis, Phailine and Laila data were analysed and reported. The central pressure deficit is an intensity measure that combines maximum wind speed, storm size, and background rotation rate. Character of cyclone is mainly related to minimum sea level pressure and maximum sustained wind speed. The outer core of winds in TCs over the BoB is asymmetric in both premonsoon and post-monsoon seasons and for all categories of intensity of TCs. On the other hand, the asymmetry in inner core winds is significantly less. The low level environment like enhanced cross equatorial flow, lower/ middle level relative humidity, vertical wind shear and proximity of TC to the land surface are the determining factors for the size and asymmetry of TCs over the North Indian Ocean (NIO) [4]. TC size should be coupled with $\mathrm{V}_{\max }$ (maximum wind velocity in the storm) rather than being treated as an independent predictor as in the current windpressure relationship, also TC intensity change should be at least coupled linearly with the radius of $V_{\max }$ [1].
There are two seasons for BoB cyclones viz., premonsoon (April-May) and post-monsoon (Oct-Dec). More number of cyclones occur in post-monsoon periods, even though track, place and intensity vary with season [5]. Wind-pressure relation is changing due to local variables and long term variables.

\section{CYCLONE TRACK AND CLIMATOLOGY}

Even though there is a steady improvement in tropical cyclone tracking, still it is challenging to predict unusual TC track, such as sharp turning or looping of TC track (Fig. 1). It is noted that TC frequency in October-November is higher than that in April-May, which is primarily attributed to the difference of mean relative humidity between the two periods [3]. IBTrACS provides the first publicly available centralized repository of global tropical cyclone besttrack data [2].

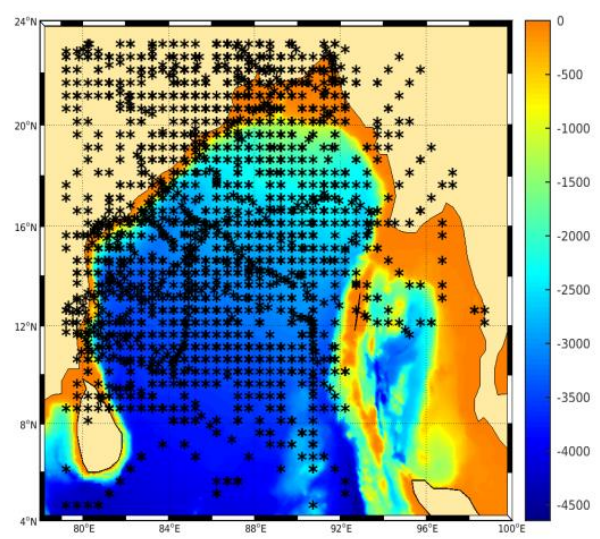

Fig. 1. Track of cyclone over Bay of Bengal during the periods 1986-2016, showing most of the cyclone having land fall over Indian coastal area. 


\section{Available online at www.ijrat.org}

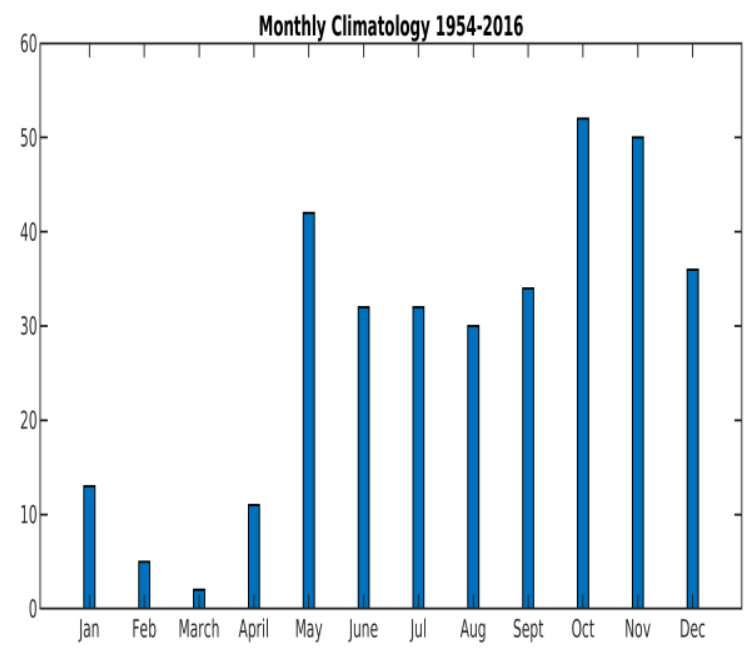

Fig. 2. Climatology of number of cyclones during the periods 1954-2016.

The eastern $\mathrm{BoB}$ is quite favourable place for cyclogenesis as oceanic thermal field in the region exhibits a warming trend, and found to extend up to a water depth of $600 \mathrm{~m}$ [5]. TC intensity, size and destructive potentials are related to sea surface temperature (SST) changes [6]. As reported in many journals, cyclone number in $\mathrm{BoB}$ is decreasing and there is an increase in trend in Arabian Sea. Warming of ocean influences frequency and intensity of cyclone in $\mathrm{BoB}$, as a result, number of cyclones is decreasing in $\mathrm{BoB}$ and at the same time, cyclone path and intensity are deviating far from prediction. As BoB is also a contributory member in global warming and climate changes, studies regarding shifting of pressure are required in the region.

\section{DATA AND METHODOLOGY}

For various reasons such as warning, post-cyclone resilience measures, etc., cyclones need to be characterized in terms of its physical properties and tracks. Correct and continuous data on cyclones are inevitable for prediction analysis to save people and property. International Best Track Archive for Climate Stewardship (IBTrACS) National Climatic Data Centre of NOAA has been doing good service to the community by compiling global cyclones data sourced from 13 public $^{1}$ and private agencies under its IBTrACS programme. It is a data repository of world cyclones and it is a time-series containing hourly data of several variables of all recorded cyclones.

Optimally, best-track data are the result of post-season reanalysis of a storm's position and intensity obtained from all available data sources like

1

Includes Regional specialized meteorological centre (RSMC), New Delhi ship, surface and satellite observations (although the level of reanalysis will vary by agency). This periodically updated data source is open to all and for free. IBTrACS provides high accuracy track data of cyclones since 1848. IBTrACS data variables are latitude, longitude, pressure, wind and time of North Indian Ocean cyclones and in CSV format. Upon analyzing IBTrACS positional data, spatial distribution of cyclones and its landfall for longer periods including track, frequency and wind pressure relations.

The 1986-2016 cyclone track data downloaded from IBTrACS through the link https://www.ncdc.noaa.gov/ibtracs/index.php?name=i btracs-data provided data on cyclones of North Indian Ocean Basin in CSV format. Data size and its CSV format forced the authors to resort to MATLAB (2015a) for processing of cyclone data. One of the authors (Mohamedali) wrote a MATLAB procedure to extract required six cyclones' multivariable time series data and to convert the CSV format of data into MATLAB acceptable format.

Variables containing data on cyclone location, wind speed, pressure and time instant were selectively picked up for easy analysis. Thus reduced time series data was used to derive a common character of cyclone in BoB; characters include monthly climatology of cyclones and relation between cyclone wind speed and pressure. Final output of MATLAB included graphs and charts which are stored in a folder for later interpretation. Using MATLAB software, data for the period 1986-2016 were gridded and interpolated for different cyclones (Fig. 5). Spatial pattern gives an idea about distribution of low pressure and maximum wind speed for the BoB.

\section{RESULT AND DISCUSSION}

Tracks show that most of the cyclones hit northwestern side of $\mathrm{BoB}$ and hence affected areas are the states of India, viz., Tamil Nadu, Andhra Pradesh and Odisha. A closer look at bathymetry (Fig. 1) and cyclone track history suggest that cyclones start and intensify over deeper ocean. Less number of cyclones originate from eastern side of $\mathrm{BoB}$ where ocean is shallow in depth. The origination of cyclones is linked with the depth of ocean. Deeper ocean promotes more cyclones. Most of the cyclones have landfall over Indian coastal area.

Most landfalls occur in north-western border of BoB. Minimum pressure and maximum wind speeds are observed in north-eastern side of BoB. Oceanic thermal field in that region turn local climate into a cyclonic favourable condition. This article describes characterisation and analyses of BoB cyclones. Cyclone data were acquired from IBTrACS 


\section{Available online at www.ijrat.org}

data repository. Mapping and analyses of cyclone data provided the following: Three fourth of the cyclones occurred during May to December months of years from 1986 to 2016 (Fig. 2). Post monsoon witnessed more cyclones.
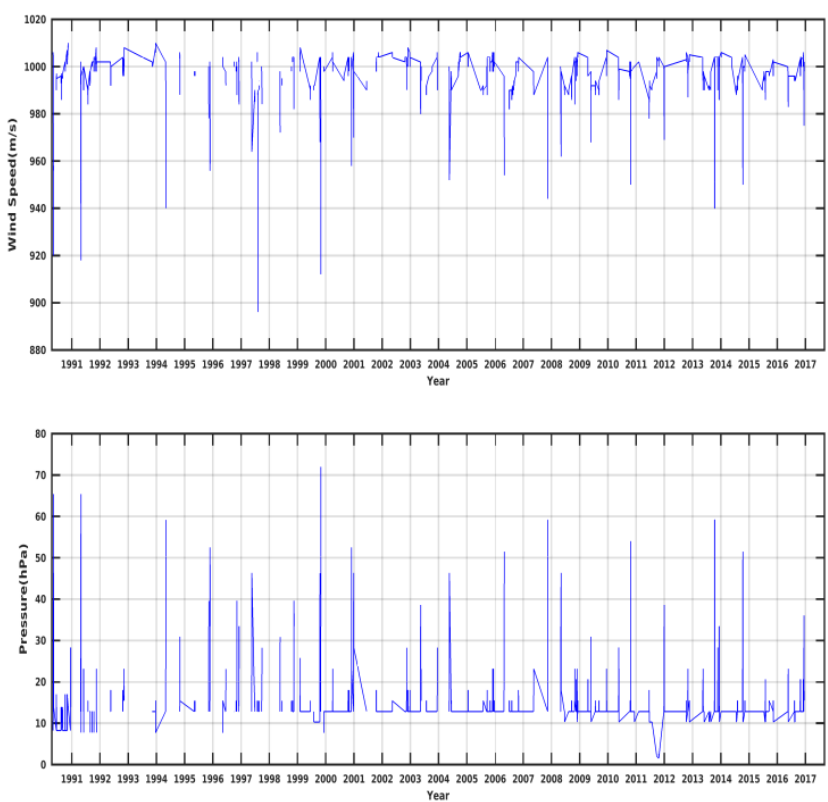

Fig. 3. Time series data from IBTrACS for the periods of 1990-2016.

\subsection{Wind-pressure relation}

Wind pressure relation is controlling track and intensity of cyclone. Fig. 3. illustrates time series of wind pressure and wind speed of cyclones occurred during the period 1990-2016. Wind pressure range is from $896 \mathrm{hPa}$ to $1010 \mathrm{hPa}$. Wind speed range is from $1.543 \mathrm{~ms}^{-1}$ to $72.02 \mathrm{~ms}^{-1}$. Comparison of Fig. 3a. with Fig. 3b. reveals a negative correspondence between wind pressure and wind speed leading to the acceptance of the logic: high speed wind blows towards low pressure zones.

Data evidently support that high wind speeds are associated with low wind pressure resulting in cyclones. It is evident from the inverse relationships between maximum wind speed and minimum wind pressure shown by plots of cyclones, viz., Vardha, Nargis, Phailine and Laila (Fig. 4a to d). Time series of cyclone data are plotted with wind pressure along primary $\mathrm{y}$-axis and wind speed along secondary $\mathrm{y}$ axis. Graphs of wind pressure and wind speed are indicative of mutual relations for different selected cyclones (Fig. 4 a-d).
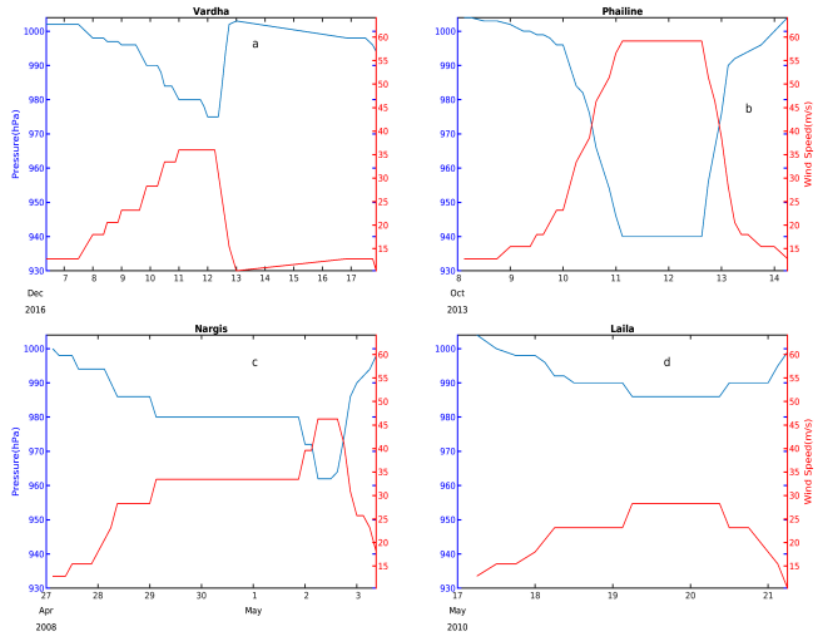

Fig. 4. Relation between minimum sea level pressure and maximum wind speed for the different cyclone.

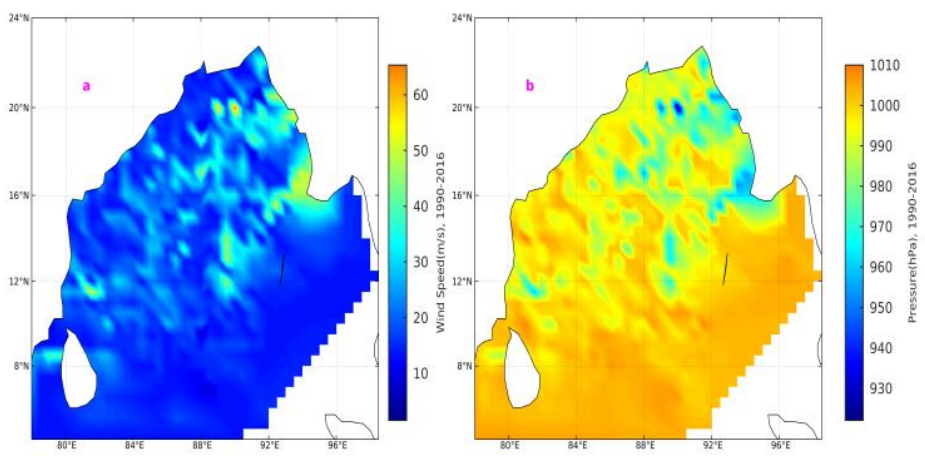

Fig. 5. Spatial pattern of pressure and wind during 1999-2016 over Bay of Bengal in different cyclone.

During the initial stage of cyclone there is a decrease in the trend of pressure and having reached the minimum the pressure shoots up to a maximum (Fig. 4a). At the same time red graph representing wind speed takes a mirrored shape of wind pressure. Gradually increasing wind speed upon attaining maximum suddenly dips to very low wind speed. Similar pattern of trends are noticeable in plots constructed for rest of the cyclones. Low pressure and high wind speed are inversely proportional which is explicit from the plots. Pressure decreases until middle of the cyclone duration and then again start to 


\section{Available online at www.ijrat.org}

increase, similarly wind speed also inversely behaves (Fig. 4a).

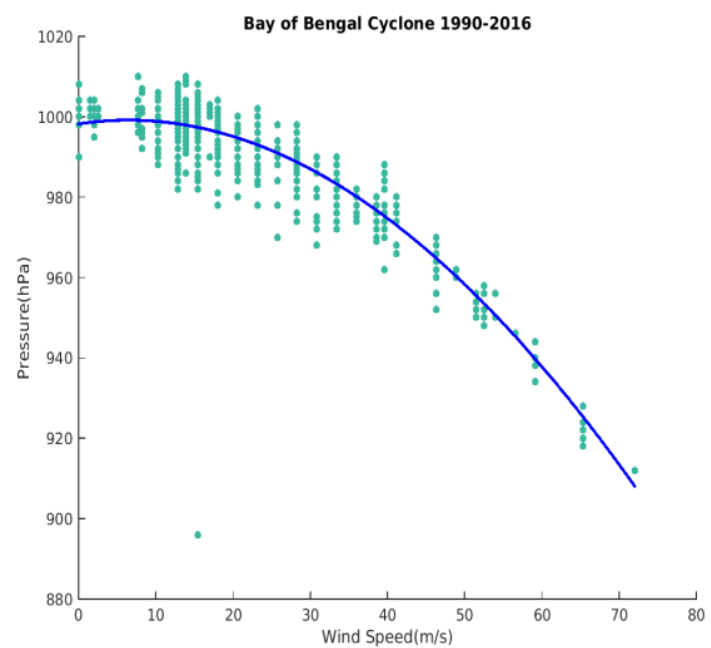

Fig. 6. Pressure-wind speed scatter plot from 19902016, over Bay of Bengal.

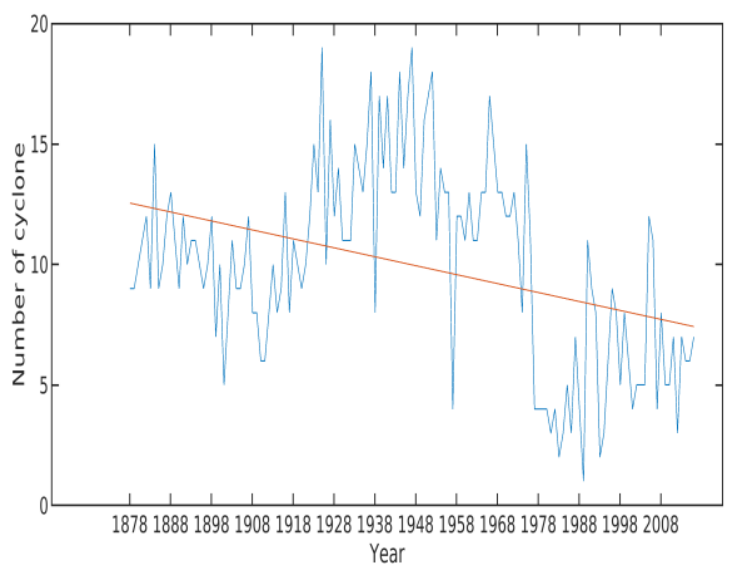

Fig. 7. Decreasing trend of number of cyclones from 1878-2016 in Bay of Bengal.

Spatial analyses of wind speed (Fig. 5a) and wind pressure (Fig. 5b) distribution over the BoB regions are also suggestive of wind-pressure relation. Fig. 6 is a bivariate scatter plot of wind pressures of $\mathrm{BoB}$ cyclones against their wind speed for the period from 1999 to 2016. The figure presents an inverse but curvilinear relationship. Low pressure system with high wind speed were predominantly located in NorthEastern region of BoB. Spatial pattern shows northeastern side of $\mathrm{BoB}$ having low pressure and maximum wind speed during most of the time and it indicates occurrence of higher intensity cyclones. Most of the BoB cyclones come within the range of 10 $\mathrm{m} / \mathrm{s}$ to $40 \mathrm{~m} / \mathrm{s}$ and pressure range was $1010 \mathrm{hPa}$ to 960 hPa (Fig. 5). Scatter plot shows negative correlation between wind speed and pressure (Fig. 6). Time series examination of number of cyclone observations during 1878-2016 reveals a decreasing trend in the cyclone occurrences in BoB; from 2004 onwards cyclone number decreased sharply (Fig. 7).

Analysis of long term data provides information about inter-annual and interdecadal variability of cyclones; it gives information about changes in frequency and in wind pressure during global warming scenario. The data from IBTrACS were analysed and have some output regarding wind pressure relation during the cyclone periods. Tropical cyclone wind is more important for mariners, ships and prediction. The characteristics of wind during cyclone will improve future prediction and research.

\section{CONCLUSION}

This article describes characterisation and analyses of BoB cyclones. MATLAB program has been a success in providing expected accuracy and precision in extracting the required six cyclones' multivariable time series data from the voluminous IBTrACS data repository. Dependency of the origination of cyclones with the depth of ocean is well documented. Most of the cyclones had their landfall across the Coromandel Coast. Three fourth of the cyclones occurred during May to December months of the years from 1986 to 2016 marking a post monsoon seasonality. Data evidently support the dictum: high wind speeds are associated with low wind pressure resulting cyclones. Cyclones, viz., Vardha, Nargis, Phailine and Laila had inverse relationships between maximum wind speed and minimum wind pressure. Similarly a curvilinear inverse relationship of wind pressures against wind speed of all cyclones for the period from 1999 to 2016 was obtained. Lower wind pressure with high wind speed systems were predominantly located in southwestern region of BoB. However, a decreasing trend in the number of incidents of cyclones is emergent when all the cyclones of the 1878-2016 period were analysed.

\section{REFERENCES}

[1] Kieu, C. Q., Chen, H., \& Zhang, D. L. (2010). An examination of the pressure-wind relationship for intense tropical cyclones. Weather and Forecasting, 25(3), 895-907.

[2] Knapp, K. R., Kruk, M. C., Levinson, D. H., Diamond, H. J., \& Neumann, C. J. (2010). The international best track archive for climate stewardship (IBTrACS) unifying tropical cyclone 
International Journal of Research in Advent Technology, Vol.7, No.1, January 2019 E-ISSN: 2321-9637

\section{Available online at www.ijrat.org}

data. Bulletin of the American Meteorological Society, 91(3), 363-376.

[3] Li, Z., Yu, W., Li, T., Murty, V. S. N., \& Tangang, F. (2013). Bimodal character of cyclone climatology in the Bay of Bengal modulated by monsoon seasonal cycle. Journal of Climate, 26(3), 1033-1046.

[4] Mohapatra, M., \& Sharma, M. (2015). Characteristics of surface wind structure of tropical cyclones over the north Indian Ocean. Journal of Earth System Science, 124(7), 15731598.

[5] Sahoo, B., \& Bhaskaran, P. K. (2015). Assessment on historical cyclone tracks in the Bay of Bengal, east coast of India. Int. Journal of Climatology, DOI, 10 .

[6] Wang, S., \& Toumi, R. (2018). Reduced Sensitivity of Tropical Cyclone Intensity and Size to Sea Surface Temperature in a RadiativeConvective Equilibrium Environment. Advances in Atmospheric Sciences, 35(8), 981-993. 